\title{
Using cluster approach and foresight technologies when designing a sustainable areas development strategy
}

\author{
Eugene Stovba ${ }^{1,}{ }^{*}$, Andrey Stovba ${ }^{1}$, Aydar Usmanov ${ }^{1}$, Aidar Sharafutdinov ${ }^{2}$, and Irek \\ Araslanbaev $^{2}$ \\ ${ }^{1}$ Birsk Branch of Bashkir State University, 452450, International Str., 10, Birsk, Russia \\ ${ }^{2}$ Bashkir State Agrarian University, 450001, 50 Years of October, 34, Ufa, Russia
}

\begin{abstract}
The article highlights the need of applying cluster approach and foresight technologies in the formation of rural areas sustainable development strategy. An algorithm, including main stages of the rural areas sustainable development strategy design based on the cluster approach and foresight technologies, is presented. Cluster scenario for the rural sustainable economic and social development in the Non-chernozem zone of the Republic of Bashkortostan has been designed, which comprehensively takes into account the results of clustering, strategic planning and foresight forecasting of rural areas development. This scenario allows us to determine the extreme and most probable target indicators values of rural areas development for the long and medium term in the cluster display.
\end{abstract}

\section{Introduction}

At the present stage of domestic economic science development, the problem of studying the phenomenon of rural areas sustainable development as certain structured local systems, is a priority direction of the national agrarian policy. Undoubtedly, achieving sustainable development should be as a target and a unique competence for each rural region of our country. Many domestic economists consider rural areas as the main resource for business and economic growth of our country and associate them with the future sustainable development of Russian regions. In economically developed countries experts widely apply the foresight technologies and cluster approach in the rural areas sustainable development design $[1,2]$.

Today clusters are one of the dialectical, multifunctional and dynamically developing economic categories. The use of the cluster approach is more effective if the grouped clusters fit into the wider context of the sustainable development strategies of the regional economy. As world practice shows, clustering, as a competitive advantages formation theory, serves not only as an effective means of achieving the agricultural policy goals, but

\footnotetext{
${ }^{*}$ Corresponding author: stovba2005@rambler.ru
} 
also is a strategic imperative for the agri-food sphere sustainable development of the of rural areas $[3,4]$.

The modern foresight methodology is based on the use of a formalized technologies system for analysis and evaluation, subsequent expertise, and designing strategies for the future rural areas development. In contrast to traditional forecasting, the result of foresight research is not only the determination of prospects and strategic reference points, but also practical measures development for their implementation $[5,6]$. The practical orientation of the cluster approach and foresight technologies increases the requirements and scientific validity of the methodological provisions being formed to develop a strategy for rural areas development, their applicability in management decision-making processes [7, 8].

\section{Materials and Methods}

The information and empirical base of the study was made up of official statistical and factual materials of national and regional departments of the Russian Federal State Statistics Service, materials of the Ministry of Agriculture of the Russian Federation and the Ministry of Agriculture of the Republic of Bashkortostan for the period from 1995 to 2019. Empirical sources are the results of a foresight exercise in devising target indicators of long-term development of rural areas conducted by the authors of the given paper.

The foresight study was based on the application of a systematic approach that involves a comprehensive assessment of elements of rural areas as a complex and balanced socioeconomic system for development and scientific justification of practical recommendations for improving organizational and methodological support for the use of foresight technologies. This process determines the analysis of the components of the development of the studied territorial system (rural areas), including the strategizing of goals and finding the relationships between their elements.

\section{Results and Discussion}

We have developed an algorithm, containing the main stages of rural areas sustainable development strategy design, based on the cluster approach and foresight technologies (Fig. $1)$.

\begin{tabular}{|c|c|}
\hline Stages of strategy design & Research methods \\
\hline 1. Analysis of conditions for the rural territories development & Foresight technologies \\
\hline$\downarrow$ & I \\
\hline $\begin{array}{l}\text { 2. Clustering rural territories by indicators of social and } \\
\text { economic development }\end{array}$ & Cluster analysis methods \\
\hline$\downarrow$ & \\
\hline $\begin{array}{l}\text { 3. Strategic planning of sustainable rural territories } \\
\text { development based on foresight methodology }\end{array}$ & $\begin{array}{l}\text { Foresight technologies } \\
\text { Scenario forecasting }\end{array}$ \\
\hline$\frac{1}{t}$ & \\
\hline $\begin{array}{l}\text { 4. Cluster scenario design for sustainable economic and social } \\
\text { development of the rural areas }\end{array}$ & $\begin{array}{l}\text { Scenario prediction } \\
\text { Cluster analysis methods }\end{array}$ \\
\hline
\end{tabular}

Fig 1. Algorithm of the rural areas sustainable development strategy design based on the cluster approach and foresight technologies. 
Modern development of rural areas of the Republic of Bashkortostan has a pronounced regional specificity due to zonal differences. From a scientific point of view, the set of rural municipal districts of the Non-chernozem zone of the republic is a model territory for designing its sustainable development, solving practical and methodological problems in achieving this goal [9]. When implementing the clustering process, statistical data file for 2016-2019, including 30 most important indicators (typological features) of the social and economic development of rural municipalities, was used. Based on the results of clustering, the proper distribution of rural municipalities of the Non-chernozem zone of the republic, including four clusters, was determined (Table 1).

Table 1. Brief description of the formed clusters.

\begin{tabular}{|c|c|c|c|c|}
\hline $\begin{array}{c}\text { Cluster } \\
\text { s }\end{array}$ & $\begin{array}{c}\text { Quantity of } \\
\text { Municipalities }\end{array}$ & $\begin{array}{c}\text { Quantity } \\
\text { of village } \\
\text { settlements }\end{array}$ & $\begin{array}{c}\text { Quantity } \\
\text { of rural } \\
\text { communities }\end{array}$ & $\begin{array}{c}\text { The density } \\
\text { of the rural } \\
\text { population, } \\
\text { people per sq. } \mathbf{~} \text { m }\end{array}$ \\
\hline I & 6 & 82 & 497 & 15.7 \\
\hline II & 3 & 47 & 277 & 8.3 \\
\hline III & 10 & 136 & 641 & 9.8 \\
\hline IV & 3 & 44 & 190 & 3.2 \\
\hline
\end{tabular}

The resulting cluster distribution of rural municipalities made it possible to reliably reflect their existing economic and social situation. According to the clustering results, the most economically «strong» cluster is first one. The second cluster is in some respects «latent» and differs mainly in average indicators of the achieved level of socio-economic development. The third cluster is the most numerous and is characterized by the highest rates of the social sphere development and, particularly, the education and health sectors. The fourth cluster has predominantly the lowest economic indicators for the rural areas development and the lowest indicators reflecting the rural areas improvement.

Successfully developing, positioning and stably functioning agricultural formations comprise the «integrator» or «core» predominantly of the first and third clusters. Organizations and enterprises that process agricultural raw materials and agri-food products are considered as «satellites» of clusters. «Growth points» determine the formation of a kind of cluster-forming block of peasant (farmer) farms and agricultural organizations of the Non-chernozem zone of the republic. Of course, the development of these «growth points» creates the potential for the formation of new clusters in the future.

Our foresight research was based on the purposeful identification and use of the experts' knowledge, namely: representatives of the legislative and executive regional authorities, the research community, the public, the media, agribusiness and the rural municipalities heads of the Republic of Bashkortostan. The process of foresight is determined by the search for preferred development scenarios and the predetermination of current decisions by the presented picture of the future. While implementing the foresighting, surveys of expert focus groups were organized and foresight forecasting of the development of the social and economic sphere of rural areas for the long term was carried out. At the pre-foresight stage, three expert groups were formed, each expert group consisted of 15-20 people, the total number of experts was 56 people. Each of the groups worked in the form of immersion workshops for discussion and analysis, independently of other expert groups.

The designed cluster scenario of sustainable social and economic development of rural areas of the Non-chernozem zone of the Republic of Bashkortostan for the long and medium term comprehensively takes into account the results of clustering, strategic planning and foresight forecasting of rural areas development and allows us to determine 
the extreme and most likely values of the target indicators of rural areas development in the cluster display (Table 2).

Table 2. Cluster scenario of sustainable social and economic development of rural areas of the Nonchernozem zone of the Republic of Bashkortostan for the period until 2030.

\begin{tabular}{|c|c|c|c|c|c|c|c|c|}
\hline \multirow{3}{*}{$\begin{array}{c}\text { Predicted } \\
\text { indicators in } \\
\text { clusters }\end{array}$} & \multicolumn{8}{|c|}{ Cluster number } \\
\hline & \multicolumn{2}{|c|}{ I } & \multicolumn{2}{|c|}{ II } & \multicolumn{2}{|c|}{ III } & \multicolumn{2}{|c|}{ IV } \\
\hline & 2025 & 2030 & 2025 & 2030 & 2025 & 2030 & 2025 & 2030 \\
\hline \multicolumn{9}{|c|}{$\begin{array}{l}\text { Investments in the basic capital, used by enterprises and organizations, } \\
\text { per capita, thousand rub. }\end{array}$} \\
\hline$\hat{y}_{\min }$ & 12.6 & 20.2 & 16.2 & 25.8 & 6.7 & 10.7 & 27.2 & 43.4 \\
\hline$\hat{y}_{\text {probable }}$ & 21.9 & 35.0 & 43.4 & 69.1 & 19.1 & 30.4 & 45.0 & 71.8 \\
\hline$\hat{y}_{\max }$ & 33.4 & 53.3 & 97.6 & 155.7 & 37.7 & 68.4 & 69.2 & 110.3 \\
\hline \multicolumn{9}{|c|}{ Agricultural production per capita, thousand rub. } \\
\hline$\hat{y}_{\min }$ & 62.4 & 77.2 & 176.1 & 229.7 & 70.5 & 87.1 & 70.2 & 86.8 \\
\hline$\hat{y}_{\text {probable }}$ & 106.9 & 132.1 & 198.5 & 245.3 & 103.7 & 128.2 & 103.0 & 127.3 \\
\hline$\hat{y}_{\max }$ & 151.8 & 187.6 & 233.5 & 288.7 & 158.3 & 195.7 & 124.5 & 154.1 \\
\hline \multicolumn{9}{|c|}{$\begin{array}{l}\text { Crop yields in all categories farms in weight after refinement, } \\
\text { center per } 1 \text { ha of harvested area }\end{array}$} \\
\hline$\hat{y}_{\min }$ & 16.5 & 17.2 & 13.1 & 13.8 & 12.6 & 16.6 & 18.0 & 19.2 \\
\hline$\hat{y}_{\text {probable }}$ & 19.3 & 20.6 & 15.5 & 16.2 & 15.7 & 17.4 & 20.5 & 21.4 \\
\hline$\hat{y}_{\max }$ & 22.9 & 23.2 & 16.8 & 17.9 & 17.6 & 19.9 & 24.5 & 25.4 \\
\hline \multicolumn{9}{|c|}{ Productivity (average annual milk yield per cow) in agricultural organizations, $\mathrm{kg}$} \\
\hline$\hat{y}_{\min }$ & 3754 & 4106 & 3781 & 4136 & 4110 & 4495 & 1653 & 1808 \\
\hline$\hat{y}_{\text {probable }}$ & 5651 & 6181 & 4933 & 5396 & 5188 & 5675 & 2086 & 2282 \\
\hline$\hat{y}_{\max }$ & 7114 & 7782 & 5939 & 6496 & 6201 & 6783 & 2400 & 2624 \\
\hline \multicolumn{9}{|c|}{$\begin{array}{l}\text { Provision of children at the age of 1-6 years old with places in pre-school educational institutions, per } 1000 \\
\text { children, places }\end{array}$} \\
\hline$\hat{y}_{\min }$ & 414.7 & 444.0 & 439.4 & 470.5 & 609.8 & 653.0 & 490.7 & 525.4 \\
\hline$\hat{y}_{\text {probable }}$ & 634.3 & 679.2 & 454.9 & 487.1 & 729.1 & 780.7 & 632.9 & 677.7 \\
\hline$\hat{y}_{\max }$ & 729.8 & 781.5 & 463.7 & 496.6 & 856.3 & 916.9 & 774.5 & 829.3 \\
\hline \multicolumn{9}{|c|}{$\begin{array}{l}\text { Coverage of children at the age of 1-6 years old with preschool } \\
\text { educational organizations, } \%\end{array}$} \\
\hline$\hat{y}_{\min }$ & 51.0 & 54.7 & 42.4 & 45.4 & 61.6 & 66.0 & 48.4 & 51.8 \\
\hline$\hat{y}_{\text {probable }}$ & 67.8 & 72.6 & 44.5 & 47.6 & 70.2 & 75.2 & 64.0 & 68.6 \\
\hline$\hat{y}_{\max }$ & 80.3 & 86.0 & 46.3 & 49.6 & 82.4 & 88.2 & 73.8 & 79.0 \\
\hline \multicolumn{9}{|c|}{ The number of hospital beds per 10000 people, units } \\
\hline$\hat{y}_{\min }$ & 35.4 & 36.1 & 45.5 & 46.4 & 38.2 & 39.0 & 37.0 & 37.7 \\
\hline$\hat{y}_{\text {probable }}$ & 39.5 & 40.2 & 58.1 & 59.3 & 60.0 & 61.2 & 52.0 & 52.9 \\
\hline$\hat{y}_{\max }$ & 45.3 & 46.2 & 80.0 & 81.5 & 125.8 & 128.2 & 76.6 & 78.0 \\
\hline \multicolumn{9}{|c|}{ The number of secondary medical personnel per 10000 people of the population, persons } \\
\hline$\hat{y}_{\min }$ & 47.9 & 48.3 & 68.5 & 69.4 & 88.1 & 88.9 & 90.8 & 91.7 \\
\hline$\hat{\mathbf{y}}_{\text {probable }}$ & 78.1 & 78.5 & 92.6 & 93.4 & 99.4 & 100.3 & 101.5 & 102.4 \\
\hline$\hat{y}_{\max }$ & 89.5 & 90.3 & 106.6 & 107.5 & 137.1 & 138.2 & 121.8 & 122.9 \\
\hline \multicolumn{9}{|c|}{ The number of doctors per 10000 people of the population, persons } \\
\hline$\hat{y}_{\min }$ & 16.9 & 17.4 & 20.1 & 20.7 & 17.9 & 18.4 & 22.1 & 22.8 \\
\hline$\hat{\mathbf{y}}_{\text {probable }}$ & 23.4 & 24.1 & 22.6 & 23.2 & 26.2 & 26.9 & 24.5 & 25.3 \\
\hline$\hat{y}_{\max }$ & 32.4 & 33.4 & 24.8 & 25.6 & 40.9 & 42.1 & 29.2 & 30.0 \\
\hline
\end{tabular}

This foresight forecast in cluster display is focused primarily on the implementation of the rural areas sustainable development scenario. Based on the use of the cluster approach 
in combination with foresight technologies, the main trends in the sustainable economic development of rural areas of the considered zone in question for the long term are formed.

\section{Conclusions}

Thus, the application of the cluster approach and foresight technologies should be one of the fundamental directions in determining key indicators of the strategy for rural areas sustainable development of the regions of the Russian Federation for the period up to 2030. The algorithm proposed in the article can serve as a reference point for improving the foresight assessment system and conducting cluster rural areas development research.

It is important to emphasize, that the research results help to shape the outline of the roadmap for the implementation of the sustainable development policy of the rural municipalities at the regional and zonal levels from the cluster approach perspective. The introduction of cluster and foresight technologies in the practice of strategic management of rural areas will contribute to the clear image formation of their future sustainable development.

\section{Acknowledgements}

The reported study was funded by RFBR and the Republic of Bashkortostan according to the research project «Strategic Planning of Economic and Social Development of Rural Areas of the Republic of Bashkortostan Based on Foresight Methodology», № 19-410020016 .

\section{References}

1. S. I. Belei, The cluster approach to the development of rural areas, The Genesis of Genius, 3-1, 32 (2014)

2. K. Cuhls, Science Technology and Innovation Policy for the Future: Potentials and Limits of Foresight Studies, 1, 199 (2013)

3. E. Feser, M. Luger, European planning studies, 11, 11 (2003)

4. Y. Polozhentseva, M. Klevtsova, International Practice Procedia Economics and Finance, 27, 529(2015)

5. Y. Yokoo, K. Okuwada, International Journal of Foresight and Innovation Policy, 8, 4, 296 (2012)

6. P. Jones, Canadian Public Administration, 60, 4, 657 (2017)

7. F.A. Costa, D.A. Fernandes, Revista de Economia Contemporanea, 20, 3, 517 (2016)

8. A. Maggio, T. Van Criekinge, J.-P. Malingreau, Foresight, 18, 5, 551 (2016)

9. E. Stovba, A. Stovba, Advances in Economics, Business and Management Research, 79, 225(2019) 